\title{
Enantioselective C-H carbene insertions with homogeneous and immobilized copper complexes
}

\author{
José M. Fraile,* Pilar López-Ram-de-Viu, José A. Mayoral, Marta Roldán, and Jorge Santafé-Valero \\ Received (in $X X X, X X X) X$ th $X X X X X X X X X 20 X X$, Accepted $X$ th $X X X X X X X X X 20 X X$ \\ DOI: 10.1039/b000000x
}

The efficiency of chiral bis(oxazoline)- and azabis(oxazoline)-copper complexes in the enantioselective carbene insertion into $\mathrm{C}-\mathrm{H}$ bonds of cyclic ethers in homogeneous phase strongly depends on the structure of the substrate. The immobilization on laponite clay by electrostatic interactions not only allows the recovery and reuse of the heterogeneous catalysts, but in some cases also improves enantioselectivity and 10 overall chemoselectivity, making possible reactions that do not take place or lead to low yields in solution, even with the commonly used $\mathrm{Rh}_{2}[S-\mathrm{DOSP}]_{4}$ catalyst.

\section{Introduction}

The great potential of carbene insertion reactions for the carboncarbon bond formation from the poorly reactive carbon-hydrogen

15 bonds has attracted considerable interest towards this type of reaction. ${ }^{1}$ Catalysis is very important to control the high reactivity of the free carbenes in order to obtain chemoselective processes. Dirhodium (II) compounds have been the most used and versatile catalysts for carbene insertions, mostly the enantioselective 20 version of both intra- and intermolecular reactions. ${ }^{2}$ Very recently the use of a salen-Ir complex as catalyst for the enantioselective insertion into THF and 1,4-cyclohexadiene has been described with very high enantioselectivity $\left(83-99 \%\right.$ ee) ${ }^{3}$ Coinage metals (copper, silver, and gold) are emerging as alternatives to 25 rhodium, ${ }^{4}$ although mostly for non-enantioselective reactions using non-chiral trispyrazolylborate and analogous ligands. ${ }^{5}$ The use of these metals in enantioselective carbene insertions is rather scarce and poor results are commonly reported. Copper complexes with chiral bis(oxazolines) and related ligands have 30 been described as catalysts for intramolecular insertions of carbenoids from phenyliodonium ylides ${ }^{6}$ or diazocompounds. ${ }^{7}$ Those reactions take place with low yields or chemoselectivities, and moderate to low enantiomeric excess, $15-60 \%$ e.e. and $6-74 \%$ e.e. respectively. Only very recently Maguire and coworkers have 35 described the efficient intramolecular insertion of a-diazosulfones with high to excellent enantioselectivities. ${ }^{8}$ Even less examples of enantioselective intermolecular carbene insertions catalyzed by metals different from rhodium can be found in the literature. A copper-bis(imine) complex was used in the synthesis of methyl 40 phenidate with low enantioselectivity $(18 \%$ e.e. $){ }^{9}$

In this context, our group described the first use of chiral bis(oxazoline)- and azabis(oxazoline)-copper complexes as catalysts for the enantioselective intermolecular carbene insertion into $\mathrm{C}-\mathrm{H}$ bonds of THF. ${ }^{10}$ The immobilization by electrostatic ${ }_{45}$ interactions on laponite clay, forming a catalyst-support ion pair, led to improved catalysts, not only in activity and recoverability,
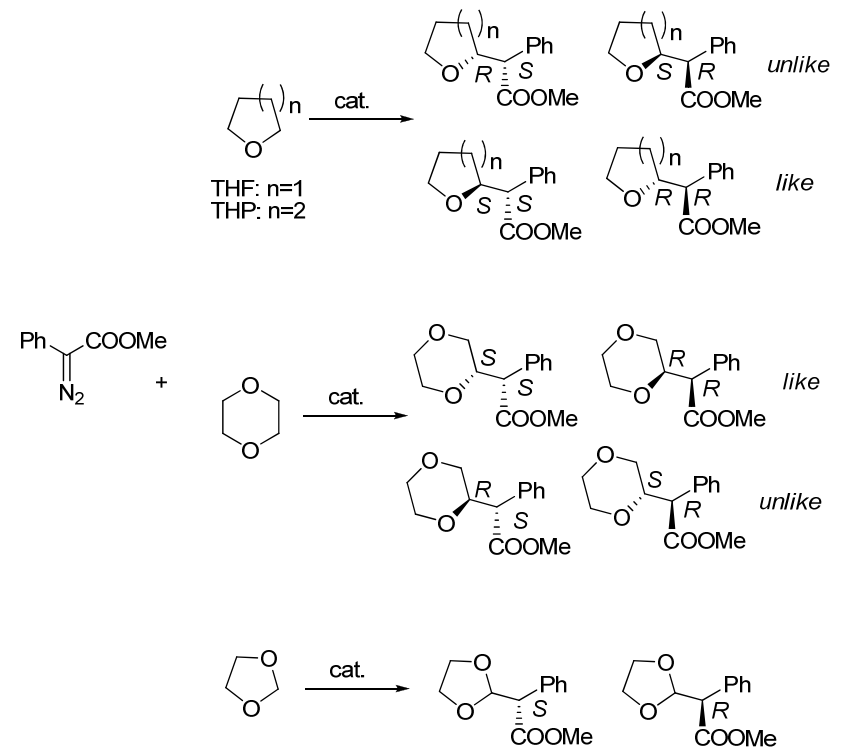

Scheme 1 Insertion reactions of methyl phenyldiazoacetate with different cyclic ethers

50 but also in enantioselectivity due to a surface effect of the support. ${ }^{11}$ In this paper we extend the study to other ethers to analyze several factors on the different selectivities (chemo-, regio-, diastereo-, and enantioselectivity) of the reactions. It is important to note that, to the best of our knowledge, the 55 enantioselective version of these reactions had not been previously described.

\section{Results and Discussion}

Reactions of methyl phenyldiazoacetate with tetrahydropyran (THP), 1,4-dioxane, and 1,3-dioxolane (Scheme 1) were studied 60 using several copper complexes with chiral bis(oxazoline) ${ }^{12}$ (1) and azabis(oxazoline) ${ }^{13}$ (2) ligands (Chart 1). For the sake of 


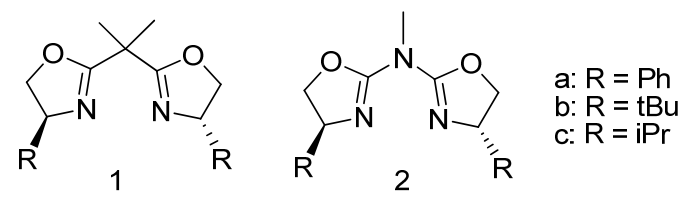

Chart 1 Oxazoline-containing ligands used along this work

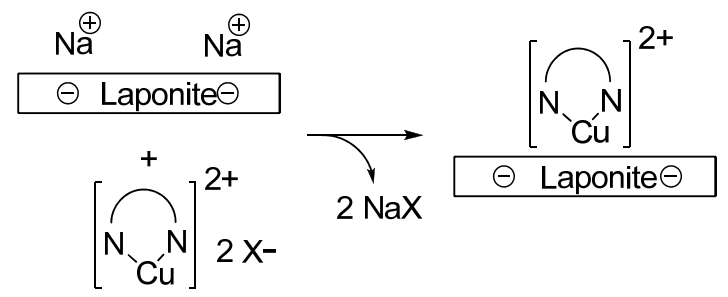

Scheme 2 Cationic exchange on laponite

5 comparison, the previously described results of the reaction with THF, ${ }^{10}$ as well as those obtained with the commercially available $\mathrm{Rh}_{2}[S \text {-DOSP }]_{4}$ catalyst, are also included (Table 1). Two diastereomers are obtained with THF, THP, and 1,4-dioxane. The unlike and like terms ${ }^{14}$ have been used instead of the syn/anti

10 nomenclature also used in the literature. In all cases homogeneous catalysts are compared, under the same conditions, with the analogous catalysts immobilized by cation exchange on laponite clay (Scheme 2), ${ }^{15}$ forming an ion pair between the clay and the cationic complex, and precluding metal leaching unless

15 copper neutral species are generated. The reactions were truly heterogeneous, as shown by the lack of activity of the filtrate, and elemental analyses showed the absence of metal leaching.

\section{Catalytic activity in C-H insertion (chemoselectivity)}

As in the case of Rh catalysts ${ }^{16}$ the conversion of diazocompound 20 to $\mathrm{C}-\mathrm{H}$ insertion products is limited by side reactions, mainly the dimerization of the diazocompound to give both cis and trans alkenes, and then the values of conversion are representative for the chemoselectivity of the reaction. Tests of insertion into THF with $1 \mathrm{a} / \mathrm{Cu}(\mathrm{OTf})_{2}$ ratios in the range of $0.8-2.0$ showed constant

25 enantioselectivities for ratios higher than 1.1 , whereas catalytic activity was reduced, demonstrating that the formation of 2:1 complexes has no positive effect on the insertion reaction. A ligand $/ \mathrm{Cu}$ ratio $=1.1$ was used with the rest of ligands and substrates in homogeneous phase. The performance of triflate 30 was shown to be better than that of other anions such as acetate, bromide, chloride, and $\mathrm{SbF}_{6}^{-}$.

All the copper triflate complexes were active for the insertion reaction, with yields in the range $40-85 \%$ for THF (Table 1, entries 2-5). A significant effect of ligand on catalytic activity 35 (chemoselectivity to insertion) is observed, with azabox ligands (2) being clearly superior, a fact that may be related to their higher coordinating ability ${ }^{17}$ and that has been also observed in other reactions. ${ }^{18}$ The substituent in position 4 of the oxazoline ring shows also an important effect on activity

40 (chemoselectivity), according to results in other reactions, ${ }^{18}$ in the order $\mathrm{Ph}>{ }^{\mathrm{i}} \mathrm{Pr}>{ }^{\mathrm{t}} \mathrm{Bu}$. This methodology was then extended to the insertion in tetrahydropyran (THP) due to the structural similarity to THF and to the interest of the insertion product as an analogue of methyl phenidate for dopamine and serotonin transporter ${ }_{45}$ inhibition. ${ }^{19}$ As can be seen (Table 1, entries 11-14) THP is less
Table 1 Results of the enantioselective reaction between methyl phenyldiazoacetate and different substrates catalyzed by copper complexes in solution and immobilized on laponite clay ${ }^{a}$

\begin{tabular}{|c|c|c|c|c|c|c|c|}
\hline Entry & Substrate & Ligand & $\begin{array}{l}\text { Type of } \\
\text { catalyst }\end{array}$ & $\begin{array}{l}\text { Conv. } \\
(\%)^{b, c}\end{array}$ & $\begin{array}{l}\text { unlike/ } \\
\text { like }^{c}\end{array}$ & $\begin{array}{c}\% \text { ee } \\
\text { unlike }^{d}\end{array}$ & $\begin{array}{l}\% \text { ee } \\
\text { like }\end{array}$ \\
\hline 1 & THF & [Rh] $^{e}$ & Homog & - & $67: 33^{f}$ & $72(90)^{f}$ & nd \\
\hline 2 & & $1 a$ & Homog & 48 & $64: 36$ & 59 & 40 \\
\hline 3 & & $2 a$ & Homog & 85 & $64: 36$ & 59 & 55 \\
\hline 4 & & $2 b$ & Homog & 54 & $74: 26$ & 0 & -12 \\
\hline 5 & & $2 c$ & Homog & 74 & $56: 44$ & 64 & 48 \\
\hline 6 & & $1 a$ & Immob & 66 & $75: 25$ & 84 & 39 \\
\hline 7 & & $2 a$ & Immob & 60 & $74: 26$ & 58 & 51 \\
\hline 8 & & $2 b$ & Immob & 27 & $51: 49$ & 4 & 16 \\
\hline 9 & & $2 c$ & Immob & 50 & $59: 41$ & 62 & 59 \\
\hline 10 & THP & {$[\mathbf{R h}]^{e}$} & Homog & $37(26)^{g}$ & $63: 37$ & $52(72)^{g}$ & $28(42)^{g}$ \\
\hline 11 & & $1 \mathbf{a}$ & Homog & 9 & $65: 35$ & 33 & 17 \\
\hline 12 & & $2 a$ & Homog & 43 & $58: 42$ & 53 & 48 \\
\hline 13 & & $2 b$ & Homog & 19 & $62: 38$ & -11 & 38 \\
\hline 14 & & 2c & Homog & 40 & $51: 49$ & 51 & 71 \\
\hline 15 & & $1 a$ & Immob & 39 & $58: 42$ & 68 & 41 \\
\hline 16 & & $2 a$ & Immob & 77 & $63: 37$ & 58 & 60 \\
\hline 17 & & 2c & Immob & 43 & $46: 54$ & 39 & 71 \\
\hline 18 & $1,4-$ & 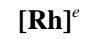 & Homog & $<1(16)^{g}$ & $39: 61$ & $-(41)^{g}$ & $-(59)^{g}$ \\
\hline 19 & dioxane & 1a & Homog & 10 & $37: 63$ & 62 & 71 \\
\hline 20 & & $2 a$ & Homog & 8 & $32: 68$ & -7 & 45 \\
\hline 21 & & $2 b$ & Homog & 3 & $43: 57$ & 0 & 0 \\
\hline 22 & & 2c & Homog & 11 & $29: 71$ & 24 & 35 \\
\hline 23 & & $1 \mathrm{a}$ & Immob & 7 & $43: 57$ & 48 & 45 \\
\hline 24 & & $2 a$ & Immob & 30 & $37: 63$ & 11 & 54 \\
\hline 25 & & $2 c$ & Immob & 38 & $30: 70$ & 36 & 50 \\
\hline 26 & $1,3-$ & 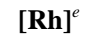 & Homog & $21(10)^{g}$ & - & $49(76)^{g}$ & - \\
\hline 27 & dioxolane & $1 a$ & Homog & 0 & - & - & - \\
\hline 28 & & 1a & Immob & 51 & - & 38 & - \\
\hline 29 & & $2 a$ & Immob & 66 & - & 33 & - \\
\hline 30 & & $2 b$ & Immob & 47 & - & 56 & - \\
\hline 31 & & $2 c$ & Immob & 76 & - & 31 & - \\
\hline
\end{tabular}

${ }^{a}$ Reaction conditions: $2 \%$ catalyst $(\mathrm{Cu} /$ diazocompound ratio), substrate as 50 solvent, slow addition $\left(2 \mathrm{~h}\right.$ ) of diazo compound, reflux. ${ }^{b}$ Conversion to insertion products. As total conversion of diazocompound was observed in all cases, this value reflects the chemoselectivity to the insertion reaction. ${ }^{c}$ Determined by GC. ${ }^{d}$ THF: determined by HPLC (Chiralcel OD-H); $(\alpha S, 2 R)$ is the major unlike product. THP: determined by GC 55 (Cyclodex- $\beta) ;(\alpha S, 2 R)$ was tentatively assigned as the major unlike product. 1,4-Dioxane and 1,3-dioxolane: determined by GC (Cyclodex- $\gamma$ ). ${ }^{e}$ Results with $\mathrm{Rh}_{2}[S \text {-DOSP }]_{4} \cdot{ }^{f}$ Ref. 16 . In parenthesis $\%$ ee at $-50^{\circ} \mathrm{C}$ (increased up to $97 \%$ ee in hexane). ${ }^{g}$ In parenthesis results at $\mathrm{rt}$.

reactive than THF and leads to moderate to low conversions (9${ }_{60} 43 \%$ ), in the same range of result obtained with commercially available $\mathrm{Rh}_{2}[S \text {-DOSP }]_{4}$ (Table 1, entry 10 ). This effect of ring size is analogous to that previously observed for N-Bocpiperidine in comparison with $\mathrm{N}$-Boc-pyrrolidine with $\mathrm{Rh}$ catalysts. $^{20}$ The donor character of the ligand ${ }^{17}$ seems to play ${ }_{65}$ again a role, with the same general trend observed for THF: $\mathbf{2 a} \geq$ $2 c>>2 b \geq 1$.

The next substrate tested was 1,4-dioxane. In spite of having four active positions for insertion, very low yields (3-11\%, up to $16 \%$ with $\mathrm{Rh}_{2}[S \text {-DOSP }]_{4}$ at $\mathrm{rt}$ ) were obtained in solution (Table 1 , 70 entries 18-22). Similar detrimental effects of the presence of an oxygen in $\beta$-position had been observed in the enantioselective insertion of methyl phenyldiazoacetate into both crown ethers and 1,2-dimethoxypropane with $\mathrm{Rh}$ catalysts, ${ }^{21}$ and in the nonenantioselective insertion of ethyl diazoacetate into 1,4-dioxane 75 with homogeneous copper $^{5 b}$ and silver scorpionates. ${ }^{22}$ The presence of a second oxygen in $\alpha$-position was tested in the case of 1,3-dioxolane. In principle position 2 in this substrate is more activated, due to the presence of the two adjacent oxygen atoms. 


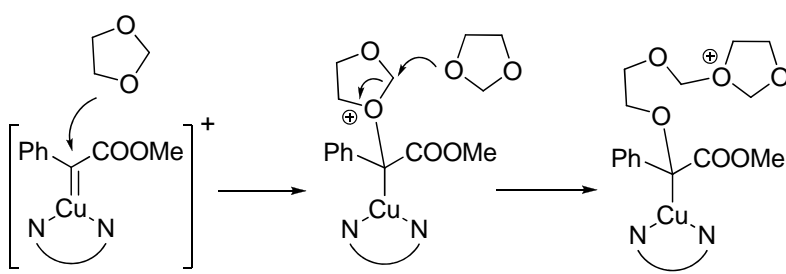

Scheme 3 Proposed mechanism for polymerization of 1,3-dioxolane

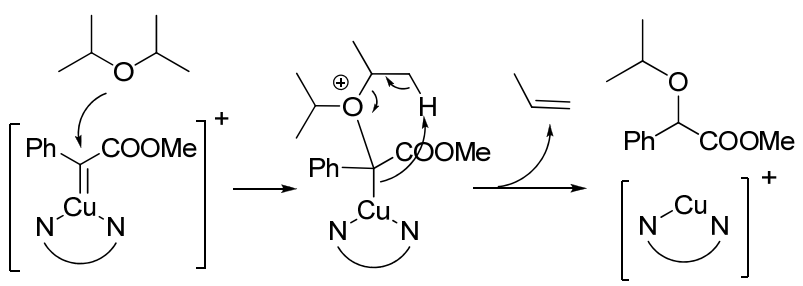

Scheme 4 Reaction between methyl phenyldiazoacetate and diisopropylether

Analogue Rh-catalyzed insertion reactions had been carried out on 2-aryl-1,3-dioxolanes, as equivalent to a Claisen condensation, ${ }^{23}$ but the insertion on the unsubstituted 1,3dioxolane, which had not been described in the literature, leads to 10 low yields (up to $21 \%$ under reflux, entry 26). Surprisingly, in the case of the homogeneous reactions with copper catalysts, the first drop of diazocompound converted the reaction solution into a gel-like mass. The ${ }^{1} \mathrm{H}-\mathrm{NMR}$ spectrum of this gel showed broad signals at $4.74(2 \mathrm{H})$ and $3.71 \mathrm{ppm}(4 \mathrm{H})$, compatible with a 15 polymer formed by dioxolane ring opening, and confirmed by the detection of species in the $\mathrm{m} / \mathrm{z}$ range of $300-1600$ with differences of 74 (Supplementary material). Even under hexane dilution conditions, the only detectable product of the homogeneous reaction was this polymer. This polymerization 20 reaction may take place through an attack of the oxygen to the electrophilic carbon of the carbenoid (Scheme 3), in the same fashion proposed for the attack of THF to carbene-iron-porphyrin complexes, in which one $\mathrm{O}-\mathrm{C}_{\alpha}$ bond is broken leading to a $\mathrm{C}-\mathrm{C}$ double bond. ${ }^{24}$ The attack of the oxygen to the carbene may occur

25 with all the substrates in a reversible way, but in this case it leads to a productive reaction. The reason for this difference is not clear but it must be related to the presence of the second oxygen, which increases the electrophilic character of the carbon in position 2 , favouring the attack of a second molecule of 1,3-dioxolane.

30 A similar behaviour would be expected in other cases in which the breakage of the $\mathrm{C}-\mathrm{O}$ was irreversible for example in the case of elimination of an alkene. Diisopropylether was chosen as model for this test, because the break of the O-C bond and the transfer of a proton would produce the elimination of propylene

35 (Scheme 4), in an irreversible step. Confirming this hypothesis the product of $\mathrm{C}-\mathrm{H}$ insertion was not detected. On the contrary the product coming from the insertion of the carbene in the $\mathrm{O}-\mathrm{H}$ bond of isopropanol was always obtained with both homogeneous and heterogeneous catalysts (Scheme 4).

40 The same reasoning would justify the lower chemoselectivity observed with 1,4-dioxane, with a breakdown process leading to methyl 2-hydroxy-2-phenylacetate, detected in the reaction medium, and volatile by-products such as acetaldehyde and ethylene.

45 Whereas immobilization is only moderately positive for chemoselectivity of insertion in THF with 1a (66\% vs 48 in solution, entries 6 and 2) and detrimental with azabis(oxazolines)
(27-60\% conversion vs $54-85 \%$ in solution, entries $7-9$ vs $3-5$ ), it has a significant positive effect with the rest of less reactive 50 substrates (Table 1). In the case of THP immobilization is highly beneficial for phenyl substituted ligands 1a (39\% vs $9 \%$ in solution, entries 15 and 11$)$ and $2 a(77 \%$ vs $43 \%$ in solution, entries 16 and 12), although this effect is not observed for the isopropyl substituted azabox 2c (entry 17). The immobilized 55 catalysts also led to moderate to excellent conversions to the expected insertion product in 1,3-dioxolane (47-76\%, entries 28 31 , in contrast with the homogeneous catalysts. Given that polymerization does not take place with the immobilized catalyst, it may be speculated the need for a coordination of both oxygens, ${ }_{60}$ making the carbon atom much more reactive, impossible with the solids due to the site isolation effect. This is not the case with diisopropyl ether, because the elimination of propylene is an intramolecular reaction. Probably the fact that breakdown in the case of 1,4-dioxolane does not require the participation of two ${ }_{65}$ molecules of catalyst makes the increase in chemoselectivity not so noticeable, with the highest values not exceeding the 30-38\% obtained using azabox ligands (entries 24-25).

It is worthy to note that insertions of methyl phenyldiazoacetate into THP, 1,4-dioxane, and 1,3-dioxolane had 70 not been previously described. Thus, taking into account the reactivity problems detected in homogeneous phase, even in the case of $\mathrm{Rh}_{2}[S \text {-DOSP }]_{4}$ and in agreement with those described for closely related substrates, the values of conversion to insertion products (77\% with THP, $38 \%$ with 1,4-dioxona, and $76 \%$ with 75 1,3-dioxolane) obtained with the immobilized catalysts are remarkable.

\section{Stereoselectivity}

The insertions into THF in homogeneous phase lead to the unlike product as major diastereoisomer with moderate to low selectivity 80 (56:44-74:26, entries 1-5). Enantioselectivities in the unlike isomer are also moderate, up to $64 \%$ ee (entry 5). Phenyl or isopropyl substituents in box and azabox lead to similar enantioselectivity, better than tert-butyl, a situation in contrast with the behaviour of the same ligands in the related 85 cyclopropanation reaction. Another important feature is the relationship between diastereoselectivity and enantioselectivity, as can be seen in Figure 1. In general lower diastereoselectivity is associated with higher enantioselectivity. The results with THF are slightly worse than those obtained with $\mathrm{Rh}_{2}(S \text {-DOSP })_{4}$ under 90 the same conditions (67:33 diastereomeric ratio, $72 \%$ ee syn, entry 1). ${ }^{16 \mathrm{~b}}$ With Rh catalysts enantioselectivity was improved by lowering the temperature or using hexane as solvent (up to $97 \%$ ee at $\left.-50^{\circ} \mathrm{C}\right) .{ }^{16 \mathrm{~b}}$ However none of those methods improved enantioselectivity in the case of 2a-Cu(OTf $)_{2}$. Enantioselectivity 95 of the like isomers follows a similar trend, up to $55 \%$ ee.

The insertions into THP in homogeneous phase also lead to the unlike product as major diastereoisomer with similar selectivity (51:49-65:35, entries 11-14), again in the same range as that obtained with Rh (entry 10). Enantioselectivities are also 100 moderate, up to $53 \%$ ee in the unlike isomers (entry 12) and up to $71 \%$ ee in the like isomers (entry 14). The substituents in box and azabox follow the same trend as that observed with THF. The results of enantioselectivity unlike with THP are similar to those obtained with $\mathrm{Rh}_{2}(S \text {-DOSP })_{4}$ under the same conditions $(52 \%$ ee, 105 entry 10 ), although in this case again enantioselectivity can be 


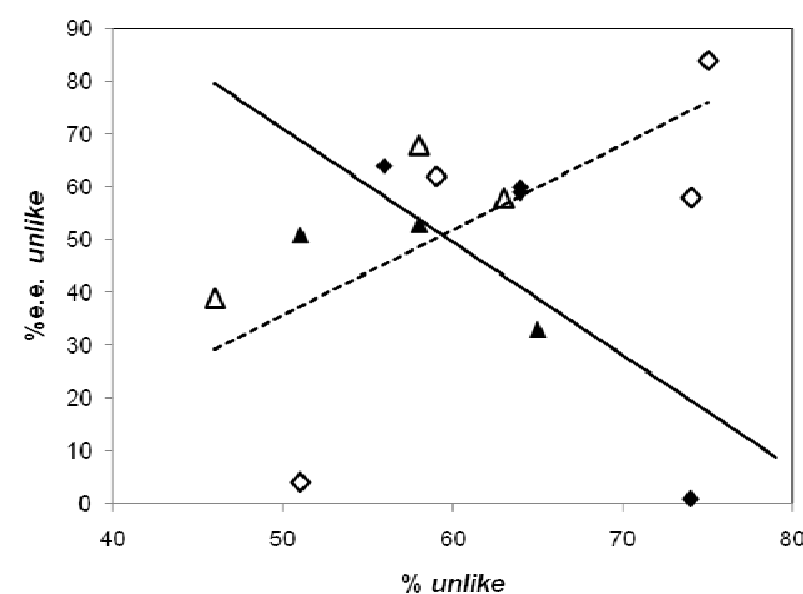

Fig. 1 Relationship between diastereo- (\% unlike) and enantioselectivity (\% ee unlike) of the reactions of methyl phenyldiazoacetate with THF ( ) and THP ( $\mathbf{\Delta}$ ) in homogeneous (filled symbols, tendency in full line) and heterogeneous (open symbols, tendency in dashed line) phase

improved by lowering the temperature. On the contrary the results of enantioselectivity like are in general better with copper complexes.

One interesting consequence of the immobilization was the 10 modification of the stereoselectivities, highly dependent on the nature of the ligand. Whereas the immobilization of azabox- $\mathrm{Cu}$ complexes produces only marginal variations of enantioselectivity (entries 7-9 and 16-17), the immobilization of 1a- $\mathrm{Cu}$ produces a significant improvement in enantioselectivity 15 of unlike isomers, $84 \%$ ee vs $59 \%$ ee in solution with THF (entry 6), $68 \%$ ee vs $33 \%$ ee in solution with THP (entry 15). Perhaps less important, but also significant, is the simultaneous variation of diastereoselectivity. In Figure 1 can be seen how the correlation between enantio- and diastereoselectivity completely 20 changes after immobilization, mainly with THF. Interestingly, with the immobilized catalysts the general trend is to obtain at the same time high diastereo- and enantioselectivity. It is important to note that the immobilized $\mathrm{Cu}$ catalysts allow reaching enantioselectivities in the same range as those obtained with ${ }_{25} \mathrm{Rh}_{2}(S \text {-DOSP })_{4}$, but in general with higher yields of insertion products.

It might be speculated whether the changes in yield and stereoselectivity are due to a surface effect, as proposed for cyclopropanation reactions, ${ }^{25}$ or to a change in the reaction 30 mechanism with the immobilized catalyst. The mechanism was checked by kinetic isotopic effect, determined by competitive reaction in the presence of equimolar amounts of THF and THF$d_{8}$. An isotopic effect $\mathrm{k}_{\mathrm{H}} / \mathrm{k}_{\mathrm{D}}=2$ was obtained for both homogeneous and heterogeneous reactions, showing that the 35 changes observed in stereoselectivities cannot be ascribed to deep changes in the reaction mechanism, but to changes in the relative energies of the transition states leading to the four products. This value is lower than that was obtained for the Rh-catalyzed reaction $\left(\mathrm{k}_{\mathrm{H}} / \mathrm{k}_{\mathrm{D}}=3\right),{ }^{16 \mathrm{~b}}$ probably due to a slightly different

40 geometry of the transition state, whereas the same value of 2 was found for the Rh-catalyzed insertion into cyclohexene. This value is in agreement with the insertion as the rate limiting step, a situation different from that of the cyclopropanation of styrene with ethyl diazoacetate promoted by the same catalysts, in which

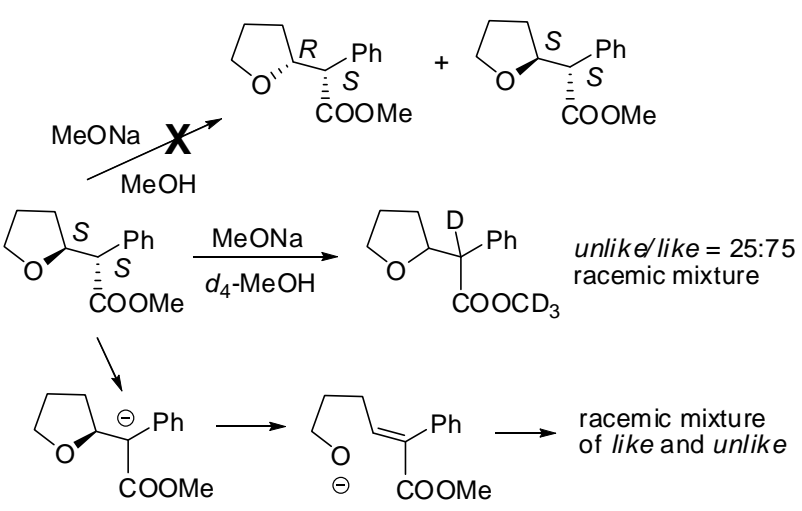

Scheme 5 Epimerization reaction of the major like product of insertion into THF

the formation of the copper-carbene intermediate is the rate limiting step. ${ }^{26}$

50 In order to get some deeper insight in the stereochemical course of the reactions, the reaction products were separated by semi-preparative chiral HPLC ${ }^{27}$ (see ESI). The four insertion products in THF were obtained in enantiopure form. In this way the absolute configuration of the major unlike product was 55 confirmed to be $(2 R, \alpha S)$ with $-88.1^{\circ}\left(\mathrm{c} 0.159, \mathrm{CHCl}_{3}\right)$. $^{\ddagger}$ The major like product showed also negative value of the specific rotation, $\quad-19.3^{\circ}\left(\mathrm{c} 0.7, \mathrm{CHCl}_{3}\right)$.

In order to check the absolute configuration, an epimerization of the $\alpha$-carbon of this product under basic conditions was tested 60 to obtain the corresponding mixture of unlike/like products with the same absolute configuration in position 2 of the furan (Scheme 5). Unexpectedly the reaction with sodium methoxide led to a 25:75 mixture of unlike:like in racemic form. To discard the possible abstraction of the proton in position 2 of THF, the ${ }_{65}$ reaction was carried out in $d_{4}$-methanol obtaining in this way the same mixture of products but deuterated only in $\alpha$-position and in the methyl ester (Scheme 5). The ring opening must then take place through a mechanism outlined in Scheme 3, similar to that proposed to explain the ring opening of bicyclic $N, O$-acetal serine 70 derivatives. ${ }^{28}$ Unfortunately this result did not allowed the absolute configuration of the like products to be determined.

With respect to the absolute configuration of the major isomer of insertion into THP, the separation by semi-preparative HPLC was performed in a similar way to that described for the products 75 of THF insertion, but in this case the separation was more difficult, due to the lower solubility of the mixture (ESI). Both unlike enantiomers were obtained in enantiopure form, but like enantiomers were obtained only as a $5 / 95$ mixture. The major unlike compound showed $\quad-76.4^{\circ}\left(\mathrm{c} 0.55, \mathrm{CCl}_{4}\right)$. Taking 80 into account the similar nature of THP and THF, the induction mechanism should be the same and $(2 R, \alpha S)$ configuration can be tentatively assigned to the major unlike product, also confirmed by the same sign of the specific rotation. Additionally the sign is also the same as the product with 2 chlorine atoms in 3,4 ${ }_{85}$ positions of the aromatic ring described in the literature. ${ }^{19 a}$

In the case of 1,4-dioxane the presence of the oxygen in the ring produces a change in the priority of the substituents of the stereogenic centre of the ring, and hence in its absolute configuration. This means that the product coming from the 90 attack by the same face will have different relative configuration unlike/like with respect to that of THP. This relative configuration 

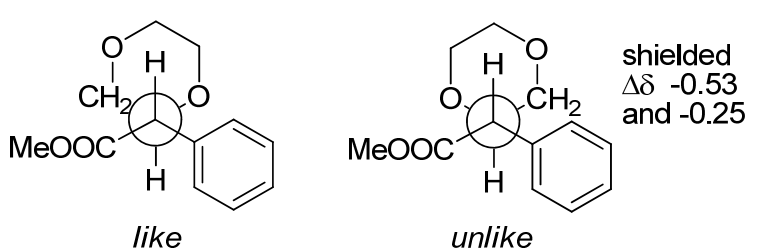

Fig. 2 Newman projections of like and unlike compounds of insertion into 1,4-dioxane

was assigned from the shielding effect of the phenyl group on 5 protons in $\mathrm{C} 3$ in the most stable antiperiplanar conformation (Figure 2) ${ }^{29}$ Due to this change, the like preference obtained with 1,4-dioxane does not represent any change in reaction mechanism.

Enantioselectivities were moderate in solution with azabox 2a 10 and 2c, whereas the highest values were obtained with box 1a (71\% ee, entry 19). This result is clearly better than that obtained with $\mathrm{Rh}_{2}[S \text {-DOSP }]_{4}$. at r.t. $(59 \%$ ee, entry 18$)$. The use of the immobilized catalysts produced variations in enantioselectivity, but without any pattern, with improvements for azabox $(50-54 \%$ 15 ee, entries $24-25)$ and reduction for box 1a ( $45 \%$ vs $71 \%$ ee in solution, entry 23 ).

In the case of 1,3-dioxolane, only products of insertion in position 2 of the dioxolane ring were detected in all cases, showing a very high regioselectivity. Products of insertion in 20 position 4 had been obtained with 2-aryl-1,3-dioxolanes as substrates, in proportions ranging from $29 \%$ at $50^{\circ} \mathrm{C}$ to $18 \%$ at $-30^{\circ} \mathrm{C}{ }^{23}$ Enantioselectivity was moderate with all the ligands, with values in the range of $31-56 \%$ ee (entries $28-31$ ). The best enantioselectivity was obtained with the ligand bearing tert-butyl

${ }_{25}$ groups $(56 \%$ ee), in contrast with results obtained with the rest of substrates. This result is analogous to that obtained with $\mathrm{Rh}_{2}[S-$ DOSP $]_{4}$ under the same conditions $(49 \%$ ee, entry 26$)$, and slightly worse than the result at r.t. (76\% ee), although this higher ee is accompanied by an important decrease in yield up to only $3010 \%$.

\section{Recoverability}

An additional advantage of immobilized catalysts is the possibility of recovery and reuse (Table 2). In the case of THF recovery was very efficient with box $1 \mathbf{a}$ in three reuses, leading to 35 a total TON of 134 with 75:25 diastereoselectivity and 83\% ee, much better than TON 24 with $64: 36$ and $59 \%$ ee of the homogeneous catalyst. With the rest of catalysts only one or two reuses were tried, with similar results to those obtained in the first run, showing the high stability of the catalysts under the reaction 40 conditions.

In the case of THP most catalysts were efficiently recovered, even with improved catalytic activity as it happens with 2c. Whereas 1a-Cu loses activity and selectivity upon recovery probably due to a partial loss of ligand, the higher stability of 2a${ }_{45} \mathrm{Cu}$ and $2 \mathrm{c}-\mathrm{Cu}$ complexes ${ }^{17}$ makes them more suitable for this reaction, keeping the activity and enantioselectivity for 3 cycles.

The low chemoselectivity of the insertion into 1,4-dioxane, with the generation of the corresponding by-products, that poison the catalyst or favor leaching of the chiral ligand, may be the 50 origin for the poor recyclability of the immobilized catalysts in this reaction. Only azabox 2c allows efficient recovery regarding both activity and selectivity in one recycle.
Table 2 Results of recovery of the copper complexes immobilized on laponite clay in the enantioselective reaction between methyl 55 phenyldiazoacetate and different substrates ${ }^{a}$

\begin{tabular}{|c|c|c|c|c|c|c|}
\hline Substrate & Ligand & Run & $\begin{array}{l}\text { Conv. } \\
(\%)^{b, c}\end{array}$ & $\begin{array}{c}\text { unlike/ } \\
\text { like }^{c}\end{array}$ & $\begin{array}{c}\% \text { ee } \\
\text { unlike }^{d}\end{array}$ & $\begin{array}{l}\% \text { ee } \\
\text { like }^{d}\end{array}$ \\
\hline \multirow[t]{11}{*}{ THF } & \multirow[t]{5}{*}{$1 \mathrm{a}$} & 1 & 66 & $75: 25$ & 84 & 39 \\
\hline & & 2 & 71 & $77: 23$ & 83 & 40 \\
\hline & & 3 & 72 & $75: 25$ & 82 & 39 \\
\hline & & 4 & 65 & $72: 28$ & 81 & 40 \\
\hline & & 5 & 37 & $54: 46$ & 28 & 24 \\
\hline & \multirow[t]{3}{*}{$2 a$} & 1 & 60 & $74: 26$ & 58 & 51 \\
\hline & & 2 & 55 & $74: 26$ & 57 & 51 \\
\hline & & 3 & 61 & $73: 27$ & 56 & 54 \\
\hline & \multirow[t]{3}{*}{ 2c } & 1 & 50 & $59: 41$ & 62 & 59 \\
\hline & & 2 & 56 & $58: 42$ & 61 & 59 \\
\hline & & 3 & 62 & $56: 44$ & 58 & 56 \\
\hline \multirow[t]{9}{*}{ THP } & \multirow[t]{3}{*}{ 1a } & 1 & 39 & $58: 42$ & 68 & 41 \\
\hline & & 2 & 25 & $55: 45$ & 33 & 16 \\
\hline & & 3 & 31 & $55: 45$ & 31 & 13 \\
\hline & \multirow[t]{3}{*}{$2 a$} & 1 & 77 & $63: 37$ & 58 & 60 \\
\hline & & 2 & 54 & $60: 40$ & 62 & 65 \\
\hline & & 3 & 59 & $59: 41$ & 58 & 59 \\
\hline & \multirow[t]{3}{*}{ 2c } & 1 & 43 & $46: 54$ & 39 & 71 \\
\hline & & 2 & 53 & $46: 54$ & 42 & 70 \\
\hline & & 3 & 57 & $47: 53$ & 36 & 67 \\
\hline \multirow[t]{9}{*}{ 1,4-dioxane } & \multirow[t]{3}{*}{ 1a } & 1 & 7 & $43: 57$ & 48 & 45 \\
\hline & & 2 & 10 & $45: 55$ & 18 & 41 \\
\hline & & 3 & 12 & $47: 53$ & 7 & 25 \\
\hline & \multirow[t]{3}{*}{$2 a$} & 1 & 30 & $37: 63$ & 11 & 54 \\
\hline & & 2 & 34 & $38: 62$ & 9 & 33 \\
\hline & & 3 & 26 & $36: 64$ & 12 & 20 \\
\hline & \multirow[t]{3}{*}{$2 c$} & 1 & 38 & $30: 70$ & 36 & 50 \\
\hline & & 2 & 37 & $28: 72$ & 30 & 46 \\
\hline & & 3 & 8 & $35: 65$ & 16 & 37 \\
\hline \multirow[t]{12}{*}{ 1,3-dioxolane } & \multirow[t]{3}{*}{ 1a } & 1 & 51 & - & 38 & - \\
\hline & & 2 & 54 & - & 27 & - \\
\hline & & 3 & 49 & - & 26 & - \\
\hline & \multirow[t]{3}{*}{$2 a$} & 1 & 66 & - & 33 & - \\
\hline & & 2 & 58 & - & 34 & - \\
\hline & & 3 & 44 & - & 30 & - \\
\hline & \multirow[t]{3}{*}{$2 \mathbf{b}$} & 1 & 47 & - & 56 & - \\
\hline & & 2 & 38 & - & 42 & - \\
\hline & & 3 & 37 & - & 36 & - \\
\hline & \multirow{3}{*}{$2 c$} & 1 & 76 & - & 31 & - \\
\hline & & 2 & 86 & - & 28 & - \\
\hline & & 3 & 85 & - & 27 & - \\
\hline
\end{tabular}

${ }^{a}$ Reaction conditions: $2 \%$ catalyst $(\mathrm{Cu}$ /diazocompound ratio), substrate as solvent, slow addition $(2 \mathrm{~h})$ of diazo compound, reflux. ${ }^{b}$ Conversion to insertion products. As total conversion of diazocompound was observed in all cases, this value reflects the chemoselectivity to the insertion 60 reaction. ${ }^{c}$ Determined by GC. ${ }^{d}$ THF: determined by HPLC (Chiralcel OD-H $) ;(\alpha S, 2 R)$ is the major unlike product. THP: determined by GC $(C y c l o d e x-\beta) ;(\alpha S, 2 R)$ was tentatively assigned as the major unlike product. 1,4-Dioxane and 1,3-dioxolane: determined by GC (Cyclodex- $\gamma$ ).

The high chemoselectivity obtained with immobilized catalysts ${ }_{65}$ in the insertion into 1,3-dioxolane, probably due to site isolation as pointed above, allows efficiently recovering the catalysts with similar enantioselectivity and even improved activity, as in the case of 2c. Unfortunately the lower stability of $\mathbf{2 b}-\mathbf{C u}$ makes the recovery inefficient, with loss of enantioselectivity.

70 It is the clear that there is a close relationship between chemoselectivity and catalyst recovery, as observed in the closely related cyclopropanation, ${ }^{30}$ because of the detrimental effect of by-products.

\section{Conclusions}

75 Homogeneous box- and azabox-copper complexes are able to 
catalyze the enantioselective insertion of methyl phenyldiazoacetate into $\mathrm{C}-\mathrm{H}$ bonds of cyclic ethers. Chemo-, diastereo-, and enantioselectivities strongly depend on the nature of the substrate. The best results are obtained with THF (up to $564 \%$ ee), whereas 1,4-dioxane is much less reactive (up to $11 \%$ conversion) and 1,3-dioxolane leads only to polymerization products.

When the same complexes are immobilized by electrostatic interactions with laponite clay, the catalytic performance 10 considerably improves. In all cases the productivity increases, either in one single reaction, up to $38 \%$ conversion with $1,4-$ dioxane vs $11 \%$ in solution, or by efficient recovery in at least three consecutive runs. Moreover, the immobilized catalysts are able to efficiently promote the insertion in position 2 of $1,3-$ 15 dioxolane, with up to $56 \%$ ee preventing the insertion in position 4 and other side reactions. An additional advantage of the immobilized catalysts is the improvement of the stereoselectivity, up to $84 \%$ ee with THF and $68 \%$ ee with THP combined with high diastereoselectivity. In summary the immobilized copper 20 complexes are promising catalysts for carbene insertion reactions, given that in the most demanding reactions they allow reaching higher chemoselectivities, with similar stereoselectivities, than the commonly used $\mathrm{Rh}_{2}(S \text {-DOSP })_{4}$ catalyst, an advantage probably due to the site isolation effect.

\section{${ }_{25}$ Experimental}

\section{General procedure for carbene insertion with heterogeneous} catalysts

A suspension of dried heterogeneous catalyst $(100 \mathrm{mg})$ in anhydrous substrate (THF, THP, 1,4-dioxane, or 1,3-dioxolane, $3010 \mathrm{~mL})$ with $\mathrm{n}$-decane $(100 \mathrm{mg})$ as internal standard was heated under reflux under an inert atmosphere. A solution of methyl phenyldiazoacetate $(1 \mathrm{mmol})$ in anhydrous substrate $(10 \mathrm{~mL})$ was slowly added during $2 \mathrm{~h}$ with a syringe pump. Once the addition had finished, the reaction mixture was stirred and heated under 35 reflux for $30 \mathrm{~min}$. The catalyst was filtered off and washed with substrate $(5 \mathrm{~mL})$. The yield and diastereoselectivity were determined by $\mathrm{GC}$ and enantioselectivities were determined by HPLC or GC. The catalyst was dried under vacuum and reused under the same conditions.

\section{${ }_{40}$ Acknowledgements}

Financial support from the Spanish Ministerio de Ciencia e Innovación (projects CTQ2008-05138 and Consolider Ingenio 2010 CSD2006-0003), and the Diputación General de Aragón (E11 Group co-financed by the European Regional Development ${ }_{45}$ Funds) is gratefully acknowledged. M. R. and J. S.-V. are indebted to DGA and CSIC respectively for their grants.

\section{Notes and references}

Departamento de Química Orgánica, Instituto de Ciencia de Materiales de Aragón and Instituto Universitario de Catálisis Homogénea, Facultad 50 de Ciencias, Universidad de Zaragoza - C.S.I.C., E-50009 Zaragoza, Spain. Fax: +34 976 762077; Tel: +34 976761000 (ext. 3514); E-mail: jmfraile@unizar.es

$\dagger$ Electronic Supplementary Information (ESI) available: experimental procedures, characterization data of every compound, and NMR spectra. ${ }_{55}$ See DOI: $10.1039 / \mathrm{b} 000000 \mathrm{x} /$ t The value reported in ref. 16 is $[\alpha]_{D}^{25}-74.0^{\circ}\left(\mathrm{c} 0.2, \mathrm{CHCl}_{3}\right)$. In our case the value obtained for the minor unlike isomer, absolute configuration $(2 S, \alpha R)$, is $[\alpha]_{D}^{25}+78.1^{\circ}\left(\mathrm{c} 0.167, \mathrm{CHCl}_{3}\right)$.

1 M. P. Doyle, R. Duffy, M. Ratnikov, L. Zhou, Chem. Rev., 2010, 110, 704.

2 H. M. L. Davies, R. E. J. Beckwith, Chem. Rev., 2003, 103, 2861.

3 H. Suematsu, T. Katsuki, J. Am. Chem. Soc., 2009, 131, 14218.

4 M. M. Díaz-Requejo, P. J. Pérez, Chem. Rev., 2008, 108, 3379.

5 M. M. Díaz-Requejo, T. R. Belderraín, M. C. Nicasio, S. Trofimenko, P. J. Pérez, J. Am. Chem. Soc., 2002, 124, 896; A Caballero, M. M. Díaz-Requejo, T. R. Belderraín, M. C. Nicasio, S Trofimenko, P. J. Pérez, Organometallics, 2003, 22, 4145; A. Caballero, M. M. Díaz-Requejo, T. R. Belderraín, M. C. Nicasio, S. Trofimenko, P. J. Pérez, J. Am. Chem. Soc., 2003, 125, 1446; H. V. R. Dias, R. G. Browning, S. A. Richey, C. J. Lovely, Organometallics, 2004, 23, 1200; J. Urbano, T. R. Belderraín, M. C. Nicasio, S. Trofimenko, M. M. Díaz-Requejo, P. J. Pérez, Organometallics, 2005, 24, 1528; G. P. A. Yap, F. Jove, J. Urbano, E. Alvarez, S. Trofimenko, M. M. Díaz-Requejo, P. J. Pérez, Inorg. Chem., 2007, 46, 780; J. Pérez, D. Morales, L. A. García-Escudero, H. Martínez-García, D. Miguel, P. Bernad, Dalton Trans., 2009, 375.

6 P. Müller, C. Boléa, Helv. Chim. Acta, 2002, 85, 483.

7 H.-J. Lim, G. A. Sulikowski, J. Org. Chem., 1995, 60, 2326; Doyle, M. P.; Hu, W. J. Org. Chem., 2000, 65, 8839; Doyle, M. P.; Phillips, I. M. Tetrahedron Lett., 2001, 42, 3155.

8 C. J. Flynn, C. J. Elcoate, S. E. Lawrence, A. R. Maguire, J. Am. Chem. Soc., 2010, 132, 1184; C. R.; Slattery, A. R. Maguire, Org. Biomol. Chem., 2011, 9, 667.

9 J. M. Axten, R. Ivy, L. Krim, J. D. Winkler, J. Am. Chem. Soc., 1999, 121, 6511

10 J. M. Fraile, J. I. García, J. A. Mayoral, M. Roldán, Org. Lett., 2007, 9, 731.

11 J. M. Fraile, J. I. García, C. I. Herrerías, J. A. Mayoral, E. Pires, Chem. Soc. Rev., 2009, 38, 695.

9012 G. Desimoni, G. Faita, K. A. Jørgensen, Chem. Rev., 2006, 106, 3561 .

13 M. Glos, O. Reiser, Org. Lett., 2000, 2, 2045; H. Werner, R. Vicha, A. Gissibl, O. Reiser, J. Org. Chem., 2003, 68, 10166.

14 IUPAC. Compendium of Chemical Terminology, (the "Gold Book") 2nd ed. (compilation A. D. McNaught, A. Wilkinson), Blackwell Scientific Publications, Oxford, 1997. XML on-line corrected version: http://goldbook.iupac.org (2006-), (compilation M. Nic, J. Jirat, B. Kosata; updates A. Jenkins). doi:10.1351/goldbook.L03423.

15 J. M. Fraile, J. I. García, C. I. Herrerías, J. A. Mayoral, M. A. Harmer, J. Catal., 2004, 221, 532.

16 H. M. L. Davies, T. Hansen, J. Am. Chem. Soc., 1997, 119, 9075; H M. L. Davies, T. Hansen, M. R. Churchill, J. Am. Chem. Soc., 2000, 122, 3063.

17 J. M. Fraile, J. I. García, C. I. Herrerías, J. A. Mayoral, O. Reiser, A Socuéllamos, H. Werner, Chem. Eur. J., 2004, 10, 2997.

18 C. Geiger, P. Kreitmeier O. Reiser, Adv. Synth. Catal., 2005, 347, 249; L. Aldea, J. M. Fraile, H. García-Marín, J. I. García, C. I. Herrerías, J. A. Mayoral, I. Pérez, Green Chem., 2010, 12, 435.

19 P. C. Meltzer, P. Wang, P. Blundell, B. K. Madras, J. Med. Chem., 2003, 46, 1538; B. K. Madras, M. A. Fahey, G. M. Miller, R. de la Garza, M. Goulet, R. D. Spealman, P. C. Meltzer, S. R. George, B. F. O’Dowd, A. A. Bonab, E. Livnid, A. J. Fischman, Eur. J. Pharmacol., 2003, 479, 41.

20 H. M. L. Davies, C. Venkataramani, T. Hansen, D. W. Hopper, J. Am. Chem. Soc., 2003, 125, 6462.

21 H. M. L. Davies, J. Yang, Adv. Synth. Catal., 2003, 345, 1133.

22 H. V. R. Dias, R. G. Browning, S. A. Richey, C. J. Lovely, Organometallics, 2004, 23, 1200.

23 H. M. L. Davies, J. Yang, J. Nikolai, J. Organomet. Chem., 2005, 690, 6111 .

24 H. M. Mbuvi, L. K. Woo, Organometallics, 2008, 27, 637.

25 A. I. Fernández, J. M. Fraile, J. I. García, C. I. Herrerías, J. A. Mayoral, L. Salvatella, Catal. Commun., 2001, 2, 165; M. R. Castillo, L. Fousse, J. M. Fraile, J. I. García, J. A. Mayoral, Chem. Eur. J., 2007, 13, 287; J. I. García, B. López-Sánchez, J. A. Mayoral, E. Pires, I. Villalba, J. Catal., 2008, 258, 378; J. M. Fraile, J. I. García, 
G. Jiménez-Osés, J. A. Mayoral, M. Roldán, Organometallics, 2008, 27, 2246.

26 J. M. Fraile, J. I. García, V. Martínez- Merino, J. A. Mayoral, L. Salvatella, J. Am. Chem. Soc., 2001, 123, 7616

527 Y. Okamoto, T. Ikai, Chem. Soc. Rev., 2008, 37, 2593.

28 C. Aydillo, G. Jiménez-Osés, J. H. Busto, J. M. Peregrina, M. M.

Zurbano, A. Avenoza, Chem. Eur. J., 2007, 13, 4840.

29 H. M. L. Davies, P. Ren, Tetrahedron Lett., 2001, 42, 3149.

30 H. Werner, C. I. Herrerías, M. Glos, A. Gissibl, J. M. Fraile, I. Pérez,

10 J. A. Mayoral, O. Reiser Adv. Synth. Catal., 2006, 348, 125. 